in the sheep fetus and newborn lamb. Circ Res 25:651

33. Reivich M, Brann AW, Shapiro H, Rawson J, Sano N 1971 Reactivity of cerebral vessels to $\mathrm{CO}_{2}$ in the newborn rhesus monkey. Eur Neurol 6:132

34. Rosenberg AA, Jones MD, Traystman RJ, Simmons MA, Molteni RA 1982 Response of cerebral blood flow to changes in $\mathrm{PCO}_{2}$ in fetal, newborn, and adult sheep. Am J Physiol 242:H862

35. Sheldon RE, Peeters LLH, Jones MD, Makowski EL, Meschia G 1979 Redistribution of cardiac output and oxygen delivery in the hypoxemic fetal lamb. Am J Obstet Gynecol 135:1071

36. Sola A, Spitzer AR, Morin FC, Schlueter MA, Phibbs RH 1983 Effects of arterial carbon dioxide tension on the newborn lamb's cardiovascular responses to rapid hemorrhage. Pediatr Res 17:70

37. Turkel SB, Miller CA, Guttenberg ME, Moynes DR, Hodgman JE 1982 A clinical pathological reappraisal of kernicterus. Pediatrics 69:267

38. Tweed,WA, Code J, Pash M, Lou H 1983 Arterial oxygenation determines autoregulation of cerebral blood flow in the fetal lamb. Pediatr Res 17:246

39. Tweed WA, Cote J, Wade JG, Gregory G, Mills A 1982 Preservation of fetal brain blood flow relative to other organs during hypovolemic hypotension. Pediatr Res 16:137

40. Vannucci RC, Hernandez MJ 1980 Perinatal cerebral blood flow. In: Sinclair JC, Warshaw JB, Bloom RS (eds) Perinatal Brain Insult. Mead Johnson Symposium on Perinatal and Developmental Medicine, No. 17. Mead Johnson, Evansville, IN, p 17

41. Vannucci RC, Duffy TED 1977 Cerebral metabolism in newborn dogs during reversible asphyxia. Ann Neurol 1:528

\title{
Splanchnic Uptake and Release of Energy Substrates in the Fasting Baboon Infant
}

\author{
LYNNE L. LEVITSKY, JOHN B. PATON, DAVID E. FISHER, AND CLARENCE W. DELANNOY \\ Departments of Pediatrics and Laboratory Animal Medicine, Michael Reese Hospital and Medical Center, \\ Pritzker School of Medicine, University of Chicago, Illinois 60616
}

\begin{abstract}
Estimates of splanchnic energy substrate exchange in the primate infant have been obtained using a baboon model. The splanchnic bed of the fasting baboon newborn released glucose at an estimated rate of $14.5 \pm$ $5.0 \mu \mathrm{mol} / \mathrm{min} \cdot \mathrm{kg}$ body weight. Splanchnic glucose release in the fasting 5-7-wk old baboon infant proceeded similarly at an estimated rate of $15.5 \pm 4.5 \mu \mathrm{mol} / \mathrm{min} \cdot \mathrm{kg}$ body weight. The principal precursors taken up by the splanchnic bed were lactate, glycerol, and alanine. Uptake of alanine correlated in a linear fashion with glucose release. Lactate was the most important precursor in both age groups. Glucose recycling through lactate is an active mechanism in the primate fetus as well as in the young of other species. (Pediatr Res 18:1316-1320, 1984)
\end{abstract}

\section{Abbreviations}

HV, estimated hepatic vein concentration

A, arterial concentration

$V_{1}$, inferior vena cava concentration below the hepatic vein

$V_{2}$, inferior vena cava above the hepatic vein

$F_{\mathrm{LC}}$, inferior vena cava flow below the hepatic vein

$F_{\text {SP, }}$ splanchnic flow

Quantitative data concerning splanchnic energy metabolism are readily available in adult man $(5,9,23,25,31)$. In contrast, information regarding splanchnic substrate exchange in the neonate and infant is derived entirely from studies in subprimate species $(3,11,24,29,30)$, isolated fetal organ studies $(1,2,10)$,

Received June 23, 1983; accepted June 8, 1984

Reprints requests should be addressed to Lynne L. Levitsky, M.D., Division of Endocrinology and Metabolism, Department of Pediatrics, Michael Reese Hospital and Medical Center, 31 st Street and Lake Shore Drive; Chicago, IL 60616.

This work was supported in part by United States Public Health Service Research Grants HD08608 and HD13138, and in part by the Medical Research Institute Council, Michael Reese Hospital and Medical Center. or inferential data derived from infusion studies, tolerance tests $(6,14)$, and stable isotope methodology (15). Previous investigations using the newly born baboon as a model for the study of neonatal energy metabolism suggest that this animal resembles the small-for-gestational-age human infant in terms of response to fasting and diminished body fat $(19,20)$. Fasting plasma arterial levels of energy substrates in the newborn of this species are similar to those found in the stressed small-for-gestationalage human neonate. Further, cerebral uptake of energy substrates is similar to that observed in human infants (19). Therefore, in the present study, we have utilized the infant baboon in order to derive estimations of comparative splanchnic energy substrate exchange in a clinically relevant model.

\section{MATERIALS AND METHODS}

Experimental animals and procedure. Baboon neonates obtained from the University of Illinois Primate Colony (Chicago IL) were the products of timed matings. Six were delivered by cesarean section at term after a 175-180-day gestation and studied at 6 to $8 \mathrm{~h}$ of life. Two of these animals were then maintained in infant incubators and fed commercial infant formula (Similac, Ross Laboratories) until studied again at 5 to 7 wk of life. Three other baboon neonates, products of spontaneous deliveries, were studied for the first time at 5 to 7 wk of life.

Under local xylocaine anesthesia, catheters (PV3, Biolabs) were placed in the aorta, the left ventricular outflow tract, and in the inferior vena cava above and below the level of the hepatic vein (Fig. 1). Catheters were kept patent with heparinized saline ( 1 unit heparin $/ \mathrm{ml}$ ). Animals were maintained under a radiant warmer during procedures and restrained, but not sedated. The stability of the animals was assessed by the stability of arterial $\mathrm{pH}$, oxygen content, lactate, hematocrit, cardiac output, and organ blood flows. Newborns were fasted from birth; animals studied at 5 to $7 \mathrm{wk}$ of life were similarly fasted for 6 to $8 \mathrm{hr}$.

Studies were carried out 2 to $4 \mathrm{hr}$ following catheter placement. Six to eight sets of three $1-\mathrm{ml}$ samples obtained from the aorta, the inferior vena cava above and below the hepatic vein were 


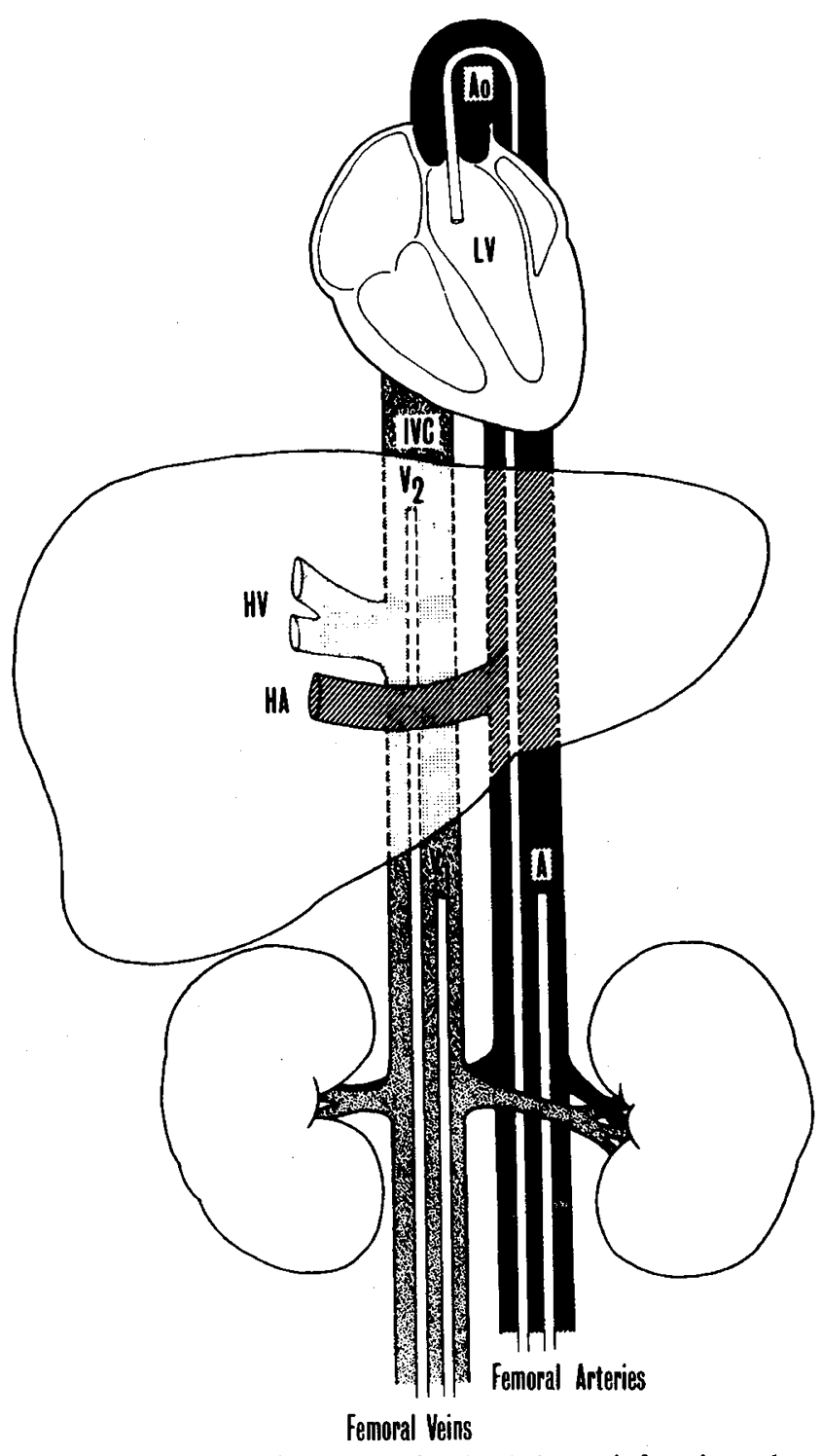

Fig. 1. Placement of catheters in the baboon infant in order to determine levels of substrates in the abdominal aorta $(A)$, and in the inferior vena cava $(I V C)$ above $\left(V_{2}\right)$ and below $\left(V_{1}\right)$ the level of the hepatic vein $(H V)$. The hepatic artery $(H A)$, thoracic aorta $(A o)$, and left ventricle $(L V)$ are indicated. Catheters were placed through the femoral vessels.

Table 1. Protocol for time and volume of blood sampling and cardiac output determinations

\begin{tabular}{cllc}
\hline \multicolumn{3}{c}{} & \multicolumn{2}{c}{$\begin{array}{c}\text { Amount of } \\
\text { blood from each } \\
\text { Time }(\mathrm{min})\end{array}$} & \multicolumn{1}{c}{ Procedure } & \multicolumn{1}{c}{$\begin{array}{c}\text { Total blood } \\
\text { withdrawn }(\mathrm{ml})\end{array}$} \\
\hline 0 & Substrate sample 1 & 1 & 3 \\
5 & Blood gâs sample 1 & 1 & 3 \\
15 & Injection of microspheres & 2 (aortic only) & 2 \\
30 & Substrate sample 2 & 1 & 3 \\
50 & Substrate sample 3 & 1 & 3 \\
60 & Blood gas sample 2 & 1 & 3 \\
70 & Substrate sample 4 & 1 & 3 \\
80 & Injection of microspheres & 2 (aortic only) & 2 \\
90 & Substrate sample 5 & 1 & 3 \\
100 & Blood gas sample 3 & 1 & 3 \\
\hline
\end{tabular}

used for substrate and blood gas determinations according to the protocol in Table 1. Blood was replaced volume for volume with heparinized placental or maternal blood in all infants following each sampling interval.
Analytic methods. Plasma samples were analyzed for glucose using a glucose oxidase oxygen electrode technique (Beckman) and for glycerol (18), lactate (22), pyruvate, alanine (16), and D$\beta$-hydroxybutyrate (28) using enzymatic fluorometric methods. Samples for pyruvate were analyzed immediately. Others were frozen at $-70^{\circ} \mathrm{C}$ until analysis. All samples except those for glucose were assayed after preparation of a 1:10 dilution of a protein-free filtrate using Centriflo membrane cones (CF-50, Amicon). All analyses of each sample were performed in triplicate, but not all substrate analyses were performed on each specimen. Each replicate set of three values $\left(A, V_{1}, V_{2}\right)$ was analyzed in the same assay run. Replicate assays were rejected and repeated if determinations varied more than $5 \%$ from the mean value. Mean values for these determinations are reported. Blood gas determinations were performed using Radiometer electrodes and meter $\mathrm{PMH} \mathrm{71}$. The $\mathrm{pH}$, and $\mathrm{Po}_{2}$ were measured directly. Oxygen content was calculated from a previously developed nomogram (27). Cardiac output and organ blood flows were computed using a radioactive microsphere technique and up to four determinations were made using different isotopic labels (26). For every study in each animal, the means of two flow measurements were used to calculate hepatic vein concentration of substrates and oxygen, and, by extension, substrate flux as well as oxygen uptake. Plasma flows were determined using a correction for hematocrit. Because hepatic vein catheterization has not proved technically feasible in this preparation, the following formula utilizing the Fick principle was employed to derive estimates of $\mathrm{HV}$, based upon determinations of $F_{\mathrm{LC}}$, $F_{S P}$, and substrate concentrations $V_{2}$ and $V_{1}$. This formula cannot be validated in the neonatal baboon, but values for glucose production derived by this technique agree well with previous data for glucose turnover in the neonate and hepatic glucose production in adult humans $(4,5,7,9,15)$.

$$
[\mathrm{HV}]=\frac{\left[\mathrm{V}_{2}\right]\left(\mathrm{F}_{\mathrm{LC}}+\mathrm{F}_{\mathrm{SP}}\right)-\left[\mathrm{V}_{\mathrm{I}}\right]\left(\mathrm{F}_{\mathrm{LC}}\right)}{\mathrm{F}_{\mathrm{SP}}}
$$

Splanchnic flow was defined as the sum of hepatic, splenic, pancreatic, and gastrointestinal flows. Calculations of hepatic vein concentrations for each animal are the means of separate computations for each set of simultaneous samples $\left(A, V_{1} V_{2}\right)$ utilizing the mean of two blood flow determinations. Arterial and venous plasma substrate levels at different ages were compared using the two-tailed Student's $t$ test. Significance of arteriohepatic venous differences for substrates was assessed by oneway analysis of variance. Arteriohepatic venous differences in the neonates and older infants were similarly evaluated by assessing intergroup variance. Comparison of lactate and alanine uptake and glucose production were made using linear regression analysis.

Enzymes for substrate analysis were obtained from BoehringerMannheim, New York (glycerokinase, glycerophosphate dehydrogenase) and Sigma, St. Louis, MO (lactic dehydrogenase, D$\beta$-hydroxybutyrate dehydrogenase, glutamic-pyruvic transaminase). Reagents used to construct standard curves were purchased from Sigma (lactic acid, DL- $\beta$-hydroxybutyrate, ketoglutarate, alanine, pyruvate), and Sargent-Welch, Chicago, IL (glycerol). NADH and NAD were purchased from Sigma. Fluorometric analyses were performed on an Aminco-Bowman SPF-15 spectrophotofluorometer. Radioactive microspheres were obtained from 3M, Minneapolis, MN.

\section{RESULTS}

The mean body weight, hepatic weight, cardiac output, blood and plasma splanchnic flows, and hematocrit of the baboon infants are shown in Table 2.

Substrate levels, $\mathrm{pH}$, oxygen content, and organ blood flows remained stable in each animal over the sampling period. The mean arterial lactate, oxygen content, and hematocrit at the beginning and end of the study were not significantly different. In the neonate, $\mathrm{pH}$ at the beginning of the study was $7.31 \pm 0.01$ 
Table 2. Weights and hemodynamic characteristics of baboon infants (mean \pm SE)

\begin{tabular}{|c|c|c|c|c|c|c|c|}
\hline Age & $\begin{array}{c}\text { Body } \\
\text { weight (g) }\end{array}$ & $\begin{array}{l}\text { Hepatic } \\
\text { weight }(\mathrm{g})\end{array}$ & $\begin{array}{l}\text { Cardiac output } \\
(\mathrm{ml} / \mathrm{min})\end{array}$ & $\begin{array}{c}\text { Adjusted } \\
\text { cardiac } \\
\text { output } \\
(\mathrm{ml} / \mathrm{min} \cdot \mathrm{kg})\end{array}$ & $\begin{array}{l}\text { Blood splanchnic } \\
\text { flow }(\mathrm{ml} / \mathrm{min})\end{array}$ & Hematocrit (\%) & $\begin{array}{l}\text { Plasma splanchnic } \\
\text { flow }(\mathrm{ml} / \mathrm{min})\end{array}$ \\
\hline
\end{tabular}

* Only one hepatic weight was obtained in this group. All other animals were not immediately sacrificed because of plans for repeated studies at 5-7 wk. Those so studied had catheters re-inserted as described.

Table 3. Levels of plasma substrates, and oxygen $(m M \pm S E)$ in the aorta, and the inferior vena cava above and below the hepatic vein: calculated hepatic vein values and substrate flux

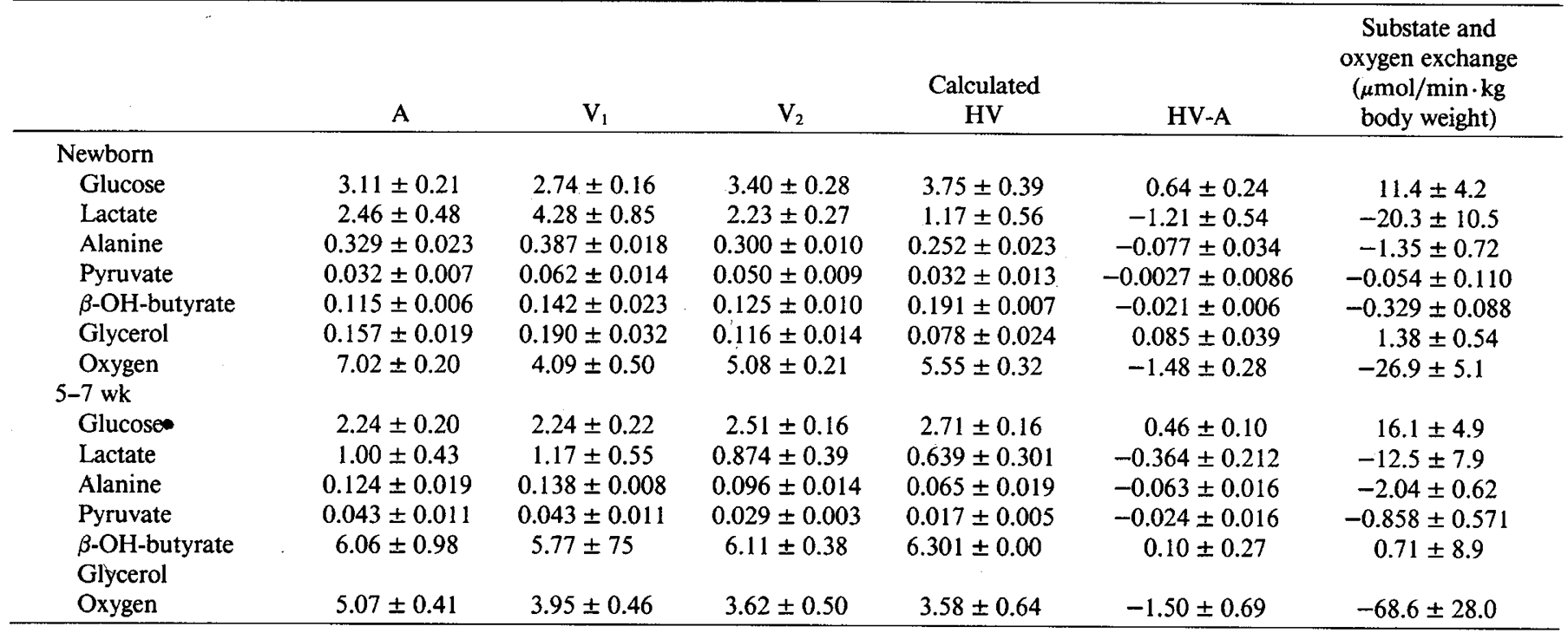

Table 4. Estimated gluconeogenic equivalents taken up by the splanchnic bed and glucose production ( $\mu \mathrm{mol} / \mathrm{min} \pm S E$ )

\begin{tabular}{lrrrrrr}
\hline & Lactate & Alanine & Pyruvate & Glycerol & Total & Glucose \\
\hline Newborn & $10.2 \pm 5.3$ & $0.68 \pm 0.36$ & $0.027 \pm 0.055$ & $0.69 \pm 0.27$ & $11.6 \pm 5.9$ & $11.4 \pm 4.2$ \\
5-7 wk & $6.2 \pm 4.0$ & $1.02 \pm 0.31$ & $0.429 \pm 0.286$ & & $7.65 \pm 4.60$ & $16.1 \pm 4.9$ \\
\hline
\end{tabular}

and at the end of the study was $7.32 \pm 0.02$. In the older infant, $\mathrm{pH}$ was $7.37 \pm 0.04$ at the beginning of the study and $7.36 \pm$ 0.03 at the end of the study; there were no significant differences over the course of the study. The mean arterial plasma glucose in the fasting newborns was $3.11 \mathrm{mM}$ or $56 \mathrm{mg} / \mathrm{dl}$, while in the 5 - to 7 -wk-old infants it was $2.24 \mathrm{mM}$ or $40.3 \mathrm{mg} / \mathrm{dl}$. This was significantly lower $(p<0.025)$.

The mean measured levels of glucose and other plasma substrates in the aorta and in the inferior vena cava above and below the hepatic vein, as well as estimated hepatic vein substrate levels, arteriohepatic venous differences, and mean computed substrate flux based on plasma splanchnic flow are detailed in Table 3. Arterial plasma alanine $(p<0.001)$ and lactate $(p<0.025)$ levels were significantly higher in the newborns compared to the older infants, and $\beta$-hydroxybutyrate was significantly higher ( $p$ $<0.001)$ in the older infants. Arterial oxygen content was higher $(p<0.005)$ in the newborn than older infants because of the higher hematocrits in the younger animals.

Arteriohepatic venous substrate differences were analyzed for significance using one-way analysis of variance. Release of glucose and uptake of lactate, alanine, and pyruvate were significant in both newborn and older animals $(p<0.005)$. $\beta$-Hydroxybutyrate was produced by the splanchnic bed of the neonate and glycerol was taken up $(p<0.01)$. Plasma $\beta$-hydroxybutyrate in the older animals was quite high, but no pattern of net uptake or release could be discerned. Glycerol was not measured in the older animals. Estimated glucose release was $14.5 \pm 5.0 \mu \mathrm{mol} /$ $\mathrm{min} \cdot \mathrm{kg}$ (95\% confidence limits, 1.6 to $27.4 \mu \mathrm{mol} / \mathrm{min} \cdot \mathrm{kg}$ ) in the newborn baboon and $15.5 \pm 4.5 \mu \mathrm{mol} / \mathrm{min} \cdot \mathrm{kg}$ body weight (95\% confidence limits, 3.1 to $27.9 \mu \mathrm{mol} / \mathrm{min} \cdot \mathrm{kg}$ ) in the 5- to 7-wk-old infants.

Arterial lactate levels correlated in a linear fashion with splanchnic lactate uptake in the animals in both age groups ( $p$ $<0.05$ ) (Fig. 2). Further, arterial lactate levels were linearly related to glucose release in the neonates $(p<0.05)$ (Fig. 3), although not in the 6-wk animals (5). Alanine uptake correlated with glucose release in a linear fashion in the group as a whole $(p<0.01)$ (Fig. 4). Oxygen uptake did not correlate with glucose production.

\section{DISCUSSION}

Fasting arterial plasma levels in these neonates were compatible with similar data obtained in human neonates. Plasma alanine levels in older infants were similar to values found in fasted older children (24), whereas neonatal values approximated those previously found in human neonates (13). Arterial lactate levels were high, but in the range seen in the physically stressed human neonate.

Because it is impossible to successfully catheterize the hepatic or umbilical vein and obtain unpooled blood in these tiny animals, all measures of hepatic vein substrate levels must be 


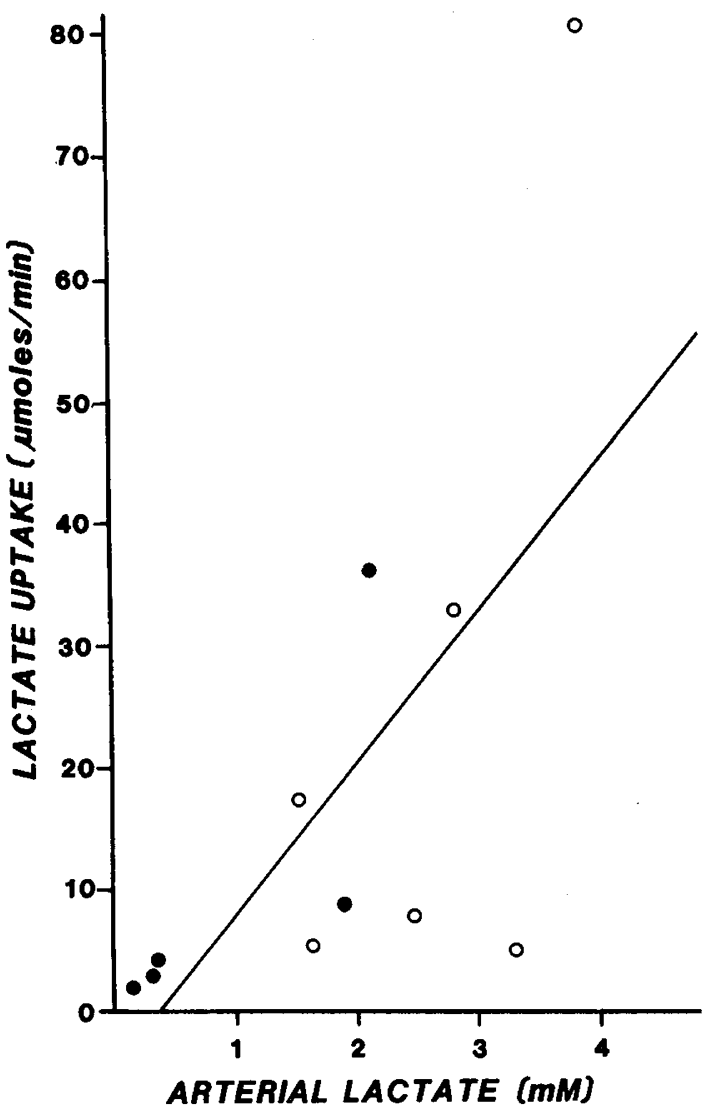

Fig. 2. Relationship of arterial lactate levels to splanchnic lactate uptake. $O$, neonates; $\bullet$, older infants $(r=0.65, p<0.05$ for both groups; $r=0.64$, neonates, and $r=0.76$, older infants; NS).

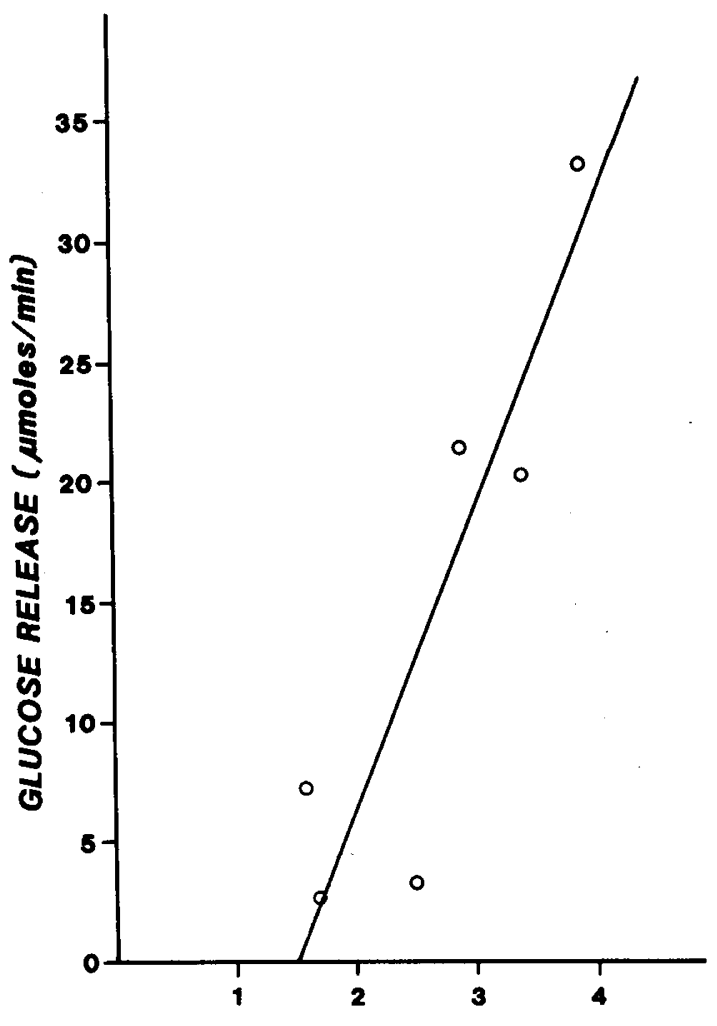

ARTERIAL LACTATE (mM)

Fig. 3. Relationship of arterial lactate levels to splanchnic glucose release in baboon neonates $(r=0.89, p<0.05)$.

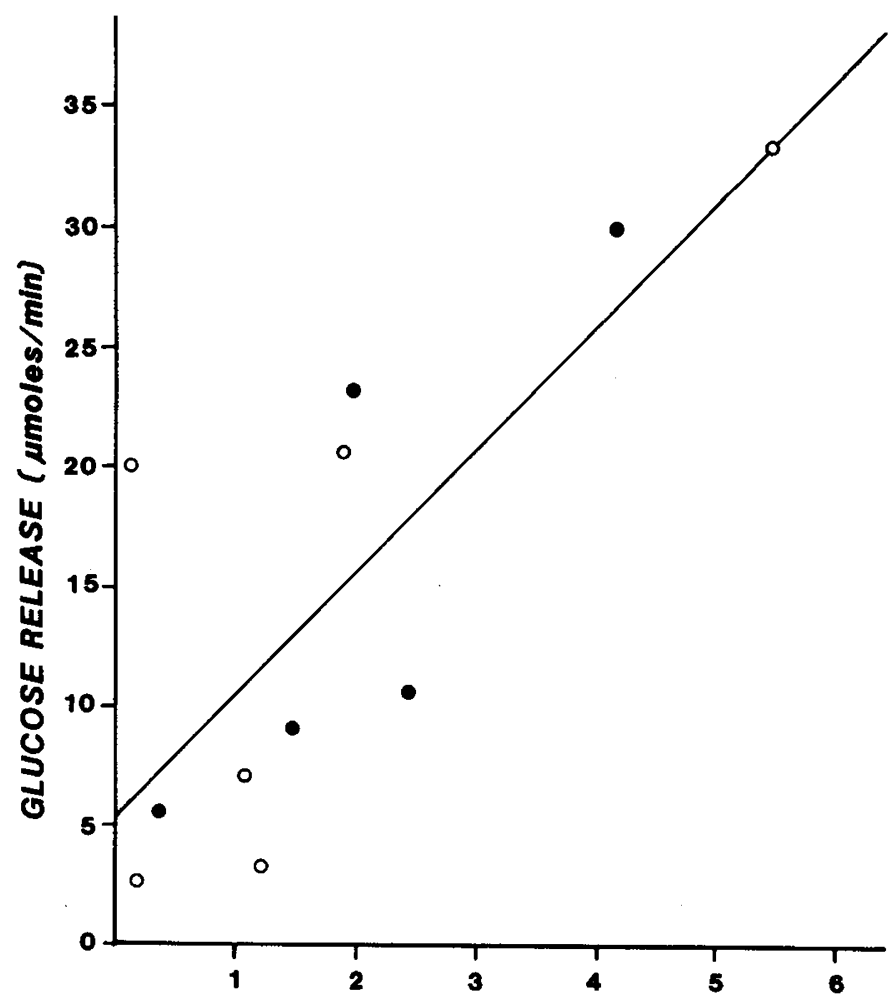

ALANINE UPTAKE ( $\mu \mathrm{mo} / \mathrm{es} / \mathrm{min}$ )

Fig. 4. Relationship of alanine uptake by the splanchnic bed to glucose release. $\bigcirc$, neonates; $\Theta$, older infants $(r=0.77, p<0.01$ for both groups; $r=0.84$ neonates, and $r=0.75$, older infants; NS).

considered estimates, and are dependent upon determinations of plasma flow. Nonetheless, these estimates afford important clues concerning the nature of splanchnic energy exchange in the primate neonate and can be compared to data obtained in man.

Free fatty acids, which are important substrates for splanchnic energy needs in the adult (12), were not measured in this study. Therefore, the energy sources for the splanchnic bed cannot be fully quantitated. We may, however, examine splanchnic glucose production and concomitant uptake of gluconeogenic substrates in these fasted animals. Through direct hepatic vein catheterization, short-term fasted man has been estimated to produce between 2 and $4 \mathrm{mg} / \mathrm{min} \cdot \mathrm{kg}$ of glucose $(5,9,23,31)$. Glucose production in the adult subjected to prolonged fasting decreases to less than one-half of that in the postabsorptive state. Stable isotope mass spectroscopy tracer findings were in the same range $(3.7-11.1 \mathrm{mg} / \mathrm{min} \cdot \mathrm{kg}$ in one study and were $4.0-4.9 \mathrm{mg} / \mathrm{min}$. $\mathrm{kg}$ in another) $(4,15)$. In contrast, hepatic glucose production by the isolated human fetal liver (1) is two to four times greater than estimated splanchnic glucose production in adult fasting man. Our estimates of hepatic glucose release of $2.6 \mathrm{mg} / \mathrm{min} \cdot \mathrm{kg}$ ( $95 \%$ confidence limits, 0.6 to $5.0 \mathrm{mg} / \mathrm{min} \cdot \mathrm{kg}$ ) in the older baboon infant are somewhat lower than the isotopic determinations of new glucose production in human infants. However, length of fasting and age of infant subjects may influence isotopically determined glucose production rates in the human neonate. It is likely, therefore, that the wide range of glucose release we have noted could be secondary not only to methodologic problems inherent in these determinations, but also to differences in nutritional status of these animals of various weights and birth histories. Certainly, the range of splanchnic glucose production rates in the fasting baboon neonates in our study approximate those previously reported in fasting adult man. These relatively low splanchnic glucose production rates compared to new glucose production rates determined in some human neonates in the postabsorptive state may reflect adaptation to fasting. Fur- 
ther, we have reported that the mean renal contribution to glucose production in the baboon neonate is $1.8 \mathrm{mg} / \mathrm{min} \cdot \mathrm{kg}$ compared to $0.6 \mathrm{mg} / \mathrm{min} \cdot \mathrm{kg}$ in the older infant baboon (20). This suggests that glucose production by liver and kidney in the neonate is approximately $4.4 \mathrm{mg} / \mathrm{min} \cdot \mathrm{kg}$ and in the older infant is approximately $3.4 \mathrm{mg} / \mathrm{min} \cdot \mathrm{kg}$. These values more closely approximate those reported using isotopic tracer techniques.

Some measured glucose release in these animals may reflect glycogenolysis rather than gluconeogenesis. Nonetheless, splanchnic uptake of gluconeogenic precursors and release of glucose, which is readily identified in these fasting, euglycemic infant primates suggests active gluconeogenesis. This adaptation to the fasting state is only a transient phenomenon. We have previously determined that fasting for more than $24 \mathrm{~h}$ may lead to marked and symptomatic hypoglycemia (19). Therefore, as in the human infant and child, the compensatory mechanisms that permit long-term euglycemic fasting in adult man are not fully developed in the infant of this primate species. Further, the substrates that contribute to hepatic glucose production in the fasting state seem to differ in their proportionate contribution in the neonatal baboon (Table 4) and adult man (8). Although estimation of substrate release and uptake rates based upon measurements of plasma flow may lead to substantial errors in the quantitation of substrate uptake and release, the estimated proportionate uptake and release of substrates in this study may be examined more closely. These determinations essentially negate the influence of plasma flow.

In the fasting newborn infant, gluconeogenic equivalents for pyruvate, alanine, and glycerol account for approximately $12 \%$ of glucose production. Lactate uptake is variable but could account for $89 \%$ of glucose production. Therefore, it is likely that lactate plays a larger precursor role in the neonate and that lactate taken up by the splanchnic bed may be substrate for other processes in addition to gluconeogenesis. In the older infant, total gluconeogenic equivalents identified as alanine ánd pyruvate uptake alone were $9 \%$ of glucose production. Glycerol uptake was not measured but may be large, as lactate uptake made up only $38.0 \%$ of gluconeogenic equivalents in these animals. Further, the role of glycogenolysis in glucose release in these animals was not assessed. In contrast to short-term fasted adult man, where alanine uptake may make up $25 \%$ of total gluconeogenic equivalents extracted by the splanchnic bed (8), alanine appeared to contribute relatively little to splanchnic gluconeogenesis in these animals. Alanine could account for only a small fraction of glucose production in the neonate and only slightly more in older infants. This suggests that changes in plasma alanine levels in fasting animals at birth and at $6 \mathrm{wk}$ reflect changes in peripheral release of alanine rather than splanchnic utilization.

The larger proportion of glucose release which could be related to lactate uptake in the newborn may be secondary to elevated levels of available lactate. Certainly, similar to reports in adult man (7), we have identified a relationship between arterial plasma lactate levels and splanchnic lactate uptake, as well as a relationship between arterial lactate and glucose release. In previous studies of renal glucose production using the same methodology, glucose production could also be related to arterial lactate (20). It may be noted that, although in adult man lactate normally accounts for less than $50 \%$ of total gluconeogenic equivalents taken up by the splanchnic bed (9), studies of the neonates of several species (29) would tend to substantiate the primacy of lactate as a gluconeogenic precursor in early life. As we have noted in studies of lactate release from peripheral tissues of the baboon neonate, glucose recycling through lactate is an active mechanism in this model and in the young of other species (21).

Acknowledgments. The authors gratefully acknowledge the excellent technical support of Ms. Jane Uehara, Ms. Jo Anne Marchichow, Ms. Audrey Paton, Ms. Nancy Hackl, and Ms. Lagrimas Munoz and the editorial assistance of Ms. Madeline
Murphy. We also thank Mr. Harry Levin for his assistance in statistical analysis and Mr. Robert Dulski for his aid in computer programming.

\section{REFERENCES}

1. Adam PAJ, Glazer C, Rogoff F, Schwartz AL, Rahiala E-L, Kekomaki M 1972 Autoregulation and evolution of glucagon control of hepatic glucose produc tion in the human fetus and canine newborn. Clin Res 20:539

2. Adam PAJ, Kekomaki M, Rahiala EL, Schwartz AL 1972 Autoregulation of glucose production by the isolated perfused human liver. Pediatr Res 6:396

3. Ballard FJ, Oliver IT 1965 Carbohydrate metabolism in liver from foetal and neonatal sheep. Biochem J 95:191-200

4. Bier DM, Leake RD, Haymond MW, Arnold KJ, Gruenke LD, Sperling MA, Kipnis DM 1977 Measurement of "true" glucose production rates in infancy and childhood with 6,6-dideuteroglucose. Diabetes 26:1016-1023

5. Bondy PK, James DF, Farrar BW 1949 Studies of the role of the liver in human carbohydrate metabolism by the venous catheter technic. I. Normal subjects under fasting conditions and following the injection of glucose. J Clin Invest 218:238-244

6. De Lamater PV, Sperling MA, Fiser RH Jr, Phelps DL, Oh WH, Fisher DA 1974 Plasma alanine: relation to plasma glucose, glucagon, and insulin in the neonate. J Pediatr 85:702-706

7. Dietze G, Wicklmayr M, Hepp KD, Bogner W, Mehnert H, Czempiel H, Henftling HG 1976 On gluconeogenesis of human liver. Accelerated hepatic glucose formation induced by increased precursor supply. Diabetologia 12:555-561

8. Felig P 1973 The glucose-alanine cycle. Metabolism 22:179-207

9. Garber AJ, Menzel PH, Boden G, Owen OE 1974 Hepatic ketogenesis and gluconeogenesis in humans. J Clin Invest 54:981-989

10. Gennser G, Lundquist I, Nilsson E 1971 Glycogenolytic activity in the liver of the human foetus. Biol Neonate 19:1-24

11. Girard JR, Cuendet GS, Marliss EB, Kervran E, Rieutort M, Assan R 1973 Fuels, hormones and liver metabolism at term and during the early postnatal period in the rat. $\mathrm{J}$ Clin Invest 52:3190-3200

12. Hagenfeldt L, Wahren J 1973 Effect of exercise on splanchnic exchange of free fatty acids. Metabolism 22:815-820

13. Haymond MW, Karl IE, Pagliara AS 1974 Ketotic hypoglycemia: an amino acid substrate limited disorder. J Clin Endocrinol Metab 38:521-530

14. Haymond MW, Karl IE, Pagliara AS 1974 Increased gluconeogenic substrates in the small-for-gestational-age infant. N Engl J Med 291:322-328

15. Kalhan SC, Savin SM, Adam PAJ 1976 Measurement of glucose turnover in the human newborn with glucose- $1-{ }^{13} \mathrm{C}$. J Clin Endocrinol Metab 43:704707

16. Karl IE, Pagliara AS, Kipnis DM 1972 A microfluorometric enzymatic assay for the determination of alanine and pyruvate in plasma and tissue. $\mathrm{J} \mathrm{Lab}$ Clin Med 80:434-441

17. King KC, Adam PAJ, Clemente GA, Schwartz R 1969 Infants of diabetic mothers: attenuated glucose uptake without hyperinsulinemia during continuous glucose infusion. Pediatrics 44:381-392

18. Laurell S, Tibbling G 1966 An enzymatic fluorometric micromethod for the determination of glycerol. Clin Chim Acta 13:317-322

19. Levitsky LL, Fisher DE, Paton JB, deLannoy CW 1977 Fasting plasma levels of glucose, acetoacetate, D- $\beta$-hydroxybutyrate, glycerol and lactate in the baboon infant: correlation with cerebral uptake of substrates and oxygen. Pediatr Res 11:298-302

20. Levitsky LL, Paton JB, Fisher DE, deLannoy CW 1980 Arterial blood levels of energy substrates and evidence for renal glucose production in the baboon infant. Pediatr Res 14:926-931

21. Levitsky LL, Paton JB, Fisher DE, deLannoy CW 1981 Uptake and release of energy substrates; oxygen and carbon dioxide by the hindlimb of the fasting infant baboon. Biol Neonate 39:105-112

22. Loomis ME 1961 An enzymatic fluorometric method for the determination of lactic acid in serum. J Lab Clin Med 57:966-969

23. Myers JD 1950 Net splanchnic glucose production in normal man and in various disease states. J Clin Invest 29:1421-1429

24. Nitzan M, Groffman H 1971 Hepatic gluconeogenèsis and lipogenesis in experimental intrauterine growth retardation in the rat. Am J Obstet Gynecol 109:623-627

25. Owen OE, Felig P, Morgan AP, Wahren J, Cahill GF Jr 1969 Liver and kidney metabolism during prolonged starvation. J Clin Invest 48:574-583

26. Paton JB, Fisher DE, Saba TM, Behrman RE 1973 Measurement of liver blood flow in the infant monkey: a comparison of methods. Biol Neonate 23:1-7

27. Paton JB, Peterson E, Fisher DE, Behrman RE 1971 Oxygen dissociation curves of fetal and adult baboons. Respir Physiol 12:283-290

28. Persson B 1969 Determination of plasma acetoacetate and D- $\beta$-hydroxybutyrate in newborn infants by an enzymatic fluorometric micromethod. Scand $\mathbf{J}$ Clin Lab Invest 25:9-18

29. Snell K, Walker DG 1973 Gluconeogenesis in the newborn rat: the substrates and their quantitative significance. Enzyme 15:40-81

30. Snell K 1974 Pathways of gluconeogenesis from L-serine in the neonatal rat. Biochem J 142:433-436

31. Wahren J, Felig P, Ahlborg G, Jorfeldt L 1971 Glucose metabolism during leg exercise in man. J Clin Invest 50:2715-2725 